\title{
Use of Antiepileptic Drugs for Nonepileptic Conditions: Psychiatric Disorders and Chronic Pain
}

\author{
Alan B. Ettinger and Charles E. Argoff \\ North Shore-Long Island Jewish Health System, New Hyde Park, New York 11040
}

\begin{abstract}
Summary: Antiepileptic drugs (AEDs) are commonly utilized for nonepileptic conditions, including various psychiatric disorders and pain syndromes. Evidence for their benefit in these nonepileptic conditions varies widely among different drugs, but there is, in general, a paucity of published multicenter randomized double-blind trials. Variable levels of evidence suggest that lamotrigine and the vagal nerve stimulator have antidepressant properties. Carbamazepine, valproate, lamotrigine, and oxcarbazepine appear to have mood stabilizing properties while gabapentin, pregabalin, and tiagabine have anxiolytic benefits. Barbiturates, topiramate, and possibly phenytoin may precipitate or exacerbate depression. Underlying
\end{abstract}

depression and anxiety symptoms may be exacerbated by levetiracetam, while psychotic symptoms have rarely been reported with topiramate, levetiracetam, and zonisamide. Pregabalin, gabapentin, carbamazepine, and oxcarbazepine have been used to treat neuropathic pain such as postherpetic neuralgia, and diabetic polyneuropathy. Topiramate and divalproex sodium have utility in the prophylaxis or acute treatment of migraine. Further rigorous studies are needed to clarify the utility of AEDs in nonepileptic conditions. Key Words: Psychotropic properties, antiepileptic drugs, depression, anxiety, psychosis, pain, neuropathic pain, migraine.

\section{INTRODUCTION}

While a large number of antiepileptic drugs (AEDs) have become available for the treatment of epilepsy, many of these agents are now utilized for conditions other than epilepsy. Two main categories of nonepileptic use are psychiatric disorders and chronic pain. This review highlights the evidence supporting utility of these agents in these two important areas.

\section{PSYCHIATRIC DISORDERS}

Although carbamazepine, valproate, and, most recently, lamotrigine ${ }^{1,2}$ are the only AEDS with a Food and Drug Administration (FDA) indication for the treatment of a psychiatric disorder, virtually every other new AED has received claims of efficacy for some psychiatric symptoms or disorders. This is due to the inadequacy of current therapeutic options for psychiatric disorders, which leads to the use of unproven treatments. ${ }^{3-5}$ For example, lithium, the gold standard for treatment of bi-

Address correspondence and reprint requests to: Alan B. Ettinger, M.D., EEG Lab, LIJMC, 270-05 76th Ave., New Hyde Park, NY 11040. E-mail: aettinge@lij.edu. polar disorder, proves to be ineffective or poorly tolerated by more than $50 \%$ of patients. The use of AEDs in psychiatric disorders is also based on the belief that there are shared biological mechanisms involved in epilepsy and these disorders.

The role of assorted neurotransmitters in both antiepileptic and psychotropic effects has become increasingly documented and may explain the utility of AEDs for psychiatric indications. ${ }^{6,7}$ The AEDs with established psychotropic effects (for example, carbamazepine, valproate, and lamotrigine) have been found to cause an increase in 5 hydroxytryptamine (5HT) ${ }^{8-10}$ The anticonvulsant protection of carbamazepine can be blocked with 5HT-depleting drugs in rats genetically prone to have seizures. ${ }^{11}$ The anticonvulsant effect of the vagal nerve stimulator (VNS) in the rat may be mediated by noradrenergic and serotonergic mechanisms, as deletion of noradrenergic and serotonergic neurons prevents or significantly reduces the anticonvulsant effect of VNS against electroshock or pentylenetetrazol-induced seizures. One may speculate that the effect of VNS on the locus coeruleus and raphe may be responsible for the antidepressant effects of the drug as identified in humans. ${ }^{12-14}$ 
Listed below, by drug, are some of the more common psychiatric applications of AEDs.

\section{Benzodiazepines}

Benzodiazepines are sometimes used in psychiatry for their anxiolytic properties. They may cause a paradoxical disinhibition syndrome characterized by agitation, aggressiveness, irritability, and hyperactivity. ${ }^{15}$ Special care should be taken to avoid abrupt withdrawal, because severe seizure exacerbation and mental status changes, including even psychosis, may occur. ${ }^{16}$

\section{Valproate}

Valproate is FDA-approved for the treatment of acute mania and mixed states. Up to $75 \%$ of patients with acute mania respond to valproate. It is also clearly effective as a maintenance treatment, but the pivotal clinical trial for this indication failed, mainly because of misjudgments in its design. The combination of divalproex with the highpotency dopamine receptor antagonist haloperidol has been linked to the development of encephalopathy. It is not clear if the same risk exists in combination with the newer antipsychotic agents.

Bowden et al. ${ }^{17}$ in a 12-month, randomized controlled trial, found median time free of episodes to be 40 weeks for divalproex, 24 weeks for lithium, and 28 weeks for placebo. Uncontrolled studies also suggest that valproate is effective for maintenance treatment of pediatric bipolar disorder, ${ }^{18}$ for the treatment of bipolar II depression, ${ }^{19}$ for agitation ${ }^{20}$ but not aggression ${ }^{21}$ associated with dementia, and for impulsive aggression ${ }^{22}$ Divalproex was similar to lithium compared with placebo in a pediatric bipolar I and II trial. ${ }^{18}$ A significant reduction in Hamilton Depression (HAM-D) scores were noted ${ }^{19}$ among 19 patients with bipolar II depression receiving divalproex for 12 weeks.

Conflicting results have been noted in open-label and controlled trials of divalproex as a treatment for agitation and aggressive behavior associated with dementia. ${ }^{20,21}$ Open trials have suggested potential efficacy of valproic acid in the treatment of panic disorder. ${ }^{23,24}$ In summary, evidence supports mood stabilizing properties for valproate. Data are conflicting with regard to potential benefits against aggressive behavior.

\section{Phenytoin}

Despite the use of phenytoin in epilepsy for many decades, the potential utility of the drug to treat bipolar disorder has only recently been evaluated. Phenytoin has been studied in controlled, albeit very small, trials of acute therapy for bipolar mania, ${ }^{25}$ maintenance treatment of bipolar disorder ${ }^{26}$ and even treatment of major depressive disorder ${ }^{27}$ or impulsive aggression. ${ }^{28}$ While some of these results are promising, much larger randomized controlled trials are needed.

\section{Carbamazepine}

Carbamazepine was approved as a treatment for acute mania in 2004, decades after it was recognized as an effective alternative to lithium in the management of bipolar illness. Open-label trials suggest that carbamazepine is effective in the prophylaxis of bipolar disorder or acute mania, but may be less effective than valproate or lithium. ${ }^{29-31}$ This, together with the side effect profile of carbamazepine, may be responsible for the much more frequent use of valproate in the treatment of bipolar disorder. However, in the neurological community, initial concerns with hematological adverse events have diminished and it remains a popular antiepileptic agent.

For example, in a randomized study in bipolar patients $^{32}$ observing the effects of carbamazepine versus lithium versus placebo, lithium was superior in preventing episodes requiring hospitalization in classic bipolar I patients, but there was a trend favoring carbamazepine for bipolar variants. Lithium was superior to carbamazepine in another notable randomized bipolar trial. ${ }^{33}$ In two multicenter studies, ${ }^{34,35}$ with patients experiencing manic or mixed episodes, carbamazepine was clearly superior to placebo.

In rare cases carbamazepine has been used to treat aggressive behavior and to facilitate sedative withdrawal, but no controlled studies are available to date to establish its efficacy in this domain. In summary, evidence is strong to support mood stabilizing properties of carbamazepine.

\section{Tiagabine}

In spite of a severe paucity of data, tiagabine has also been touted as a treatment for generalized anxiety disorder, post-traumatic stress disorder, insomnia, cocaine addiction, and impulse control disorder. Its use may be limited, however, by reports of risks of new onset seizures and status epilepticus in patients without epilepsy. $^{36}$

In an open-label trial of tiagabine $(\mathrm{n}=20)$ and paroxetine $(n=20)$ for generalized anxiety disorder, both drugs significantly decreased HAM-D scores from baseline to week $10 .{ }^{37}$ Among 17 patients with treatmentrefractory bipolar I or II disorder who received adjunctive tiagabine, 13 finished at least two weeks of therapy (only three achieved scores of "much" or "very much improved" on the Clinical Global Impressions Scale for Bipolar Disorder (CGI-BD) scale, whereas 10 had no change or worsened). ${ }^{38}$ Tiagabine was found to be similarly ineffective in a case series of eight patients with acute mania. ${ }^{39}$

\section{Gabapentin}

Despite a flurry of mostly anecdotal reports of the benefits of the drug in diverse psychiatric disorders when gabapentin was introduced, the few controlled studies ultimately performed provided, at best, mixed results. 
Most notably, gabapentin failed to demonstrate antimanic properties. Some later studies, however, suggested that it might be of some benefit in social anxiety disorder, insomnia, and post-traumatic stress disorder. ${ }^{40-42}$ For example, in a study of patients with social phobia, those treated with gabapentin $(n=34)$ showed a significantly greater reduction in scores on the Liebowitz Social Anxiety Scale compared with placebo recipients $(\mathrm{n}=35 ; p$ $=0.008){ }^{40}$

Animal studies and several small, uncontrolled clinical trials show that gabapentin may reduce alcohol withdrawal symptoms. In a comparison with phenobarbital, the severity of alcohol withdrawal craving decreased at similar rates in both treatment groups. Gabapentin, however, has not been shown to prevent alcohol withdrawal seizures. ${ }^{43}$ An open-label study of 20 institutionalized patients with probable Alzheimer's disease who received gabapentin found reductions in behavioral and psychotic symptoms. $^{44}$

In summary, there is little evidence for gabapentin to support previous anecdotal impressions about potential benefits in bipolar disorder. However, it may have significant anxiolytic effects.

\section{Pregabalin}

Preliminary evidence indicates that the new analogue of gabapentin, pregabalin, is effective for the treatment of generalized anxiety disorder. ${ }^{45}$ At a dose of $300 \mathrm{mg}$, the pregabalin-treated group differed statistically in global improvement at treatment endpoint not only from the placebo group but also from a comparator group treated with alprazolam. Doses of $600 \mathrm{mg}$ have shown notable anxiolytic effects. ${ }^{46}$ Pregabalin has not been studied for use in other mood disorders.

\section{Lamotrigine}

Lamotrigine is approved for maintenance treatment of bipolar disorder. Well designed randomized trials have convincingly demonstrated its efficacy in the treatment of bipolar depression ${ }^{47-49}$ and in promoting longer manic-free periods in bipolar I disorder. ${ }^{50}$ However, lamotrigine did not perform significantly better than placebo in the prophylaxis of rapid-cycling bipolar disorder in a large controlled trial. ${ }^{50}$

Compared with lithium, lamotrigine is better at delaying or preventing the occurrence of depression during long-term treatment. Lithium is considered, however, to be more effective than lamotrigine in preventing mania or hypomania. In bipolar patients who are depressed and not already taking lamotrigine, it should be considered for use as an alternative to an antidepressant. Some positive effect on mood should become evident as soon as two to three weeks into treatment. Lamotrigine has also shown efficacy compared with placebo in controlling impulsive aggression in one controlled trial. ${ }^{34}$

\section{Levetiracetam}

Little is known about the psychiatric effects of levetiracetam in a nonepileptic population. Small studies also suggest that the drug possesses anxiolytic and mood stabilizing properties. In epilepsy patients, it promotes depression or anxiety symptoms in approximately $8-16 \%$ of cases and especially among those with underlying mood or anxiety disorders. ${ }^{51-53}$ Levetiracetam-induced reversible psychotic symptoms have been reported in children. ${ }^{54}$

Two open-label trials of levetiracetam add-on therapy showed improvement in mania scores of patients with bipolar spectrum disorders $(\mathrm{n}=30$, combined total $)$, and, in one trial of levetiracetam for social anxiety disorder, levetiracetam improved Liebowitz Social Anxiety Scale scores in the 20 treated patients. ${ }^{55-57}$ However, these results need to be replicated in larger trials.

\section{Zonisamide}

The efficacy of zonisamide was investigated in 62 treatment-resistant outpatients with bipolar spectrum disorders in an eight-week open-label acute-phase trial, and in a subsequent 48 -week continuation trial. ${ }^{58}$ Mania and bipolar depression symptoms improved. Overall, there was a high incidence of withdrawal due to worsening mood symptoms (32\% [20 of 62]). Among 10 patients with bipolar depression treated with zonisamide, five of the eight patients who completed eight weeks of treatment had reductions of depression symptoms. ${ }^{59}$ Zonisamide for mood disorders has not been evaluated in formal primary depression trials. In Japan, clinical experience in epilepsy patients revealed a comparatively high rate of AED-related psychosis linked to use of zonisamide.

\section{Oxcarbazepine}

Potential positive psychotropic properties of oxcarbazepine are based predominantly upon its structural relationships with carbamazepine and the mood stabilizing reputation of the latter. However, there is a paucity of specific studies in either the epilepsy or the psychiatric population.

Small, older trials suggest that it is effective for bipolar disorder. ${ }^{60,61}$ In a small recent study, 4 of 12 consecutively admitted acutely manic patients with bipolar I or II disorder responded to oxcarbazepine 900 to $2100 \mathrm{mg}$ /day with a reduction of their Young Mania Rating Scale score by $50 \%$ or more from baseline. ${ }^{62}$ Oxcarbazepine was administered as add-on therapy to 16 patients with bipolar I or II disorder who were experiencing mania, depression, or a mixed episode despite ongoing lithium therapy. At the end of the eight-week trial, 11 of the patients had achieved a response, defined as a CGIbipolar disorder (CGI-BD) improvement section score of 2 or 1 (much or very much improved). ${ }^{61}$ Overall, how- 
ever, data are too limited to establish the presence of significant mood stabilizing properties with this drug.

\section{Topiramate}

Topiramate has been reported to be an effective mood stabilizer in multiple open-label studies and case reports. ${ }^{63-66}$ Rigorously performed, controlled trials, however, failed to find any benefit from use of this drug in bipolar disorder. ${ }^{67}$

Topiramate has been commonly prescribed for patients with bipolar disorder, not only because of the expectation that it will prove to be efficacious, but also because of its weight-reducing effects, which are felt to be particularly desirable to counteract the weight gain induced by some other mood stabilizing agents (e.g., valproic acid). ${ }^{68}$

Psychotic symptoms have been infrequently reported with the administration of topiramate in adults ${ }^{69}$ and children and adolescents ${ }^{70}$ with epilepsy, as well as in psychiatric patients. ${ }^{71}$ Psychotic symptoms have included severe psychomotor agitation, aggressiveness toward others, and auditory and visual hallucinations, as well as paranoid and mystical delusions. ${ }^{72}$ Risk factors may include use of topiramate in the context of polytherapy ${ }^{73}$ and a prior psychiatric history. ${ }^{69,74,75}$

Cognitive impairment is the most common complaint of psychiatric patients taking topiramate. Depression may accompany cognitive impairment or occur independently. Anecdotally, however, some patients report improved mood with this drug.

Two controlled trials suggest that topiramate may be effective for anger and aggression associated with borderline personality disorder. ${ }^{76,77}$ An open-label study of 22 institutionalized, intellectually disabled adults treated with topiramate found improvements in challenging or maladaptive behavior. ${ }^{78}$ A notable prospective open-label study found improvements in nonhallucinatory posttraumatic stress disorder symptoms with topiramate. ${ }^{79}$

In summary, evidence does not support mood stabilizing properties for topiramate and it may induce cognitive deficits and depression. However, further studies may demonstrate its efficacy for alternative psychiatric conditions.

\section{VAGUS NERVE STIMULATION}

Vagus nerve stimulation is an implantable pulse generator that stimulates the left vagus nerve and is used to reduce the frequency and severity of seizures. It has recently been FDA-approved for treatment-resistant depression. The efficacy of VNS for treatment-resistant depression was evaluated in a randomized, controlled acute-phase trial with a one-year continuation. ${ }^{80}$ Of 266 participants enrolled in the acute-phase trial, 235 received the implanted VNS device; subsequently, 112 received active treatment and 110 received sham treatment (i.e., the implanted device was not activated). After 10 weeks, there were statistically significant improvements on the Inventory of Depressive Symptomatology (IDS)-Self Report (IDS-SR; a secondary measure for depression) and a trend for the primary measure (HAM-D) for VNS versus sham treatment. While the failure to show statistical significance on the primary measure raised questions about the antidepressant effect of VNS, a progressive improvement in effect (comparable with the increasing antiepileptic efficacy seen with treatment beyond 10 weeks) was shown in the continuation study.

In this latter study, 205 patients were evaluated, including patients with sham treatment converted to active VNS after the acute phase. This analysis showed a significantly higher IDS-SR response rate after 12 months than in a control group drawn from a separate study of patients with treatment-resistant depression who received usual care without VNS $(17.0 \%$ vs $7.3 \%$; $p=$ 0.032). ${ }^{81}$ While the failure to use any randomization method in the long-term continuation study and the use of a separate naturalistic study to provide a control group provoked much controversy, many contend that the depression remission rates achieved with VNS are compelling. Common adverse effects included voice alteration, hoarseness, cough, shortness of breath, dysphagia, and neck pain. The device can be turned on and off and can be programmed externally. In summary, VNS appears to have antidepressant effects that may be more sustained than typical antidepressant therapies.

\section{CHRONIC PAIN SYNDROMES}

Anticonvulsant medications are currently commonly used in treatment of a number of chronic pain states. In fact, several of these agents are FDA-approved for the treatment of specific pain syndromes; these are discussed first. A subsequent discussion concerns agents that are not FDA-approved but are, nevertheless, commonly used in an off-label manner.

While the specific mechanisms of AED effects are incompletely understood, it is intuitive that they may be able to dampen many of the proposed causes of chronic pain, such as peripheral sensitization, central sensitization, wind-up, hyperexcitability, neuronal disinhibition, and ectopic impulse formation. For example, abnormal activation of the NMDA receptor is believed to be an integral part of kindling in epilepsy as well as wind-up in neuropathic pain; consequently, pharmacologic agents that suppress this excitation may explain their utility in both conditions. Sodium channel activation may also be common to both disorders. ${ }^{82}$ 


\section{Pregabalin}

Pregabalin is FDA-approved for the treatment of neuropathic pain associated with diabetic polyneuropathy (DPN) as well as for post-therapeutic neuralgia (PHN). Dworkin et al. ${ }^{83}$ have demonstrated in a randomized placebo-controlled trial that, for patients with PHN, pregabalin-treated patients at doses of 300 or $600 \mathrm{mg}$ each day had significantly reduced pain by the first day of treatment, and that by the end of this eight-week study the proportion of patients achieving at least $30 \%$, or at least $50 \%$, pain relief was significantly higher in those patients treated with pregabalin. In a separate randomized controlled PHN trial, Sabatowski et al. ${ }^{84}$ found that, at a dose of $300 \mathrm{mg} /$ day compared with placebo, patients receiving pregabalin not only had significant pain reduction but also enjoyed improvement in sleep and mood. In another eight-week randomized placebo-controlled trial, Rosenstock et al. ${ }^{85}$ evaluated the potential efficacy of pregabalin in reducing pain associated with DPN. Use of pregabalin at a dose of $300 \mathrm{mg}$ /day resulted in significant improvements in mean pain scores, the patient, and clinical global impression of change scores on the Short Form-36 Health Survey, and mean sleep interference scores. The improvement in pain relief and sleep began during the first week of use. These results were confirmed in a separate, similar study completed by Lesser et al. ${ }^{86}$ in patients with DPN. In this study, however, both a $300 \mathrm{mg}$ and $600 \mathrm{mg}$ daily dose were shown to be superior to placebo, although there was no significant difference between the 300 and $600 \mathrm{mg} /$ day dose. Compared with placebo, both the 300 and $600 \mathrm{mg}$ dose groups showed significant improvements in mean pain scores, sleep interference, and patient global impression of change, as well as the clinical impression of change. The improvements in pain and sleep were seen within the first week. Other published studies have confirmed these results for DPN and PHN. ${ }^{87,88}$

In an eight-week multicenter randomized controlled study, pregabalin at $450 \mathrm{mg} /$ day was found to reduce significantly the average severity of pain in patients with fibromyalgia. Other benefits included improvement in sleep quality and fatigue. ${ }^{89}$ Pregabalin is the newest available anticonvulsant and it has clearly been shown to be an effective analgesic.

\section{Gabapentin}

Gabapentin is FDA-approved for the treatment of PHN. Rice et al., ${ }^{90}$ in the Postherapetic Neuralgia Study Group, demonstrated in a multicenter double-blind randomized placebo-controlled seven-week trial that gabapentin at both 1800 and $2400 \mathrm{mg} /$ day was superior to placebo in the treatment of the PHN. More patients treated with gabapentin at either dose reported a $50 \%$ or greater reduction in pain than did placebo-treated patients; significant analgesia occurred as early as the first week of treatment. No significant differences were seen between the $1800 \mathrm{mg}$ and $2400 \mathrm{mg} /$ day treatment groups. In a separate multicenter study, the results of an eightweek randomized controlled trial demonstrated significant pain reduction for gabapentin compared with placebo in PHN. Sleep interference was also noted less in the treated group. Patients were titrated to a maximal dose of $3600 \mathrm{mg} /$ day in this study. ${ }^{91}$

Evidence also supports use of gabapentin in painful diabetic neuropathy, complex regional pain syndrome, migraine headache, spinal cord injury, phantom limb, and other neuropathic pain syndromes. ${ }^{92-95}$ The efficacy and safety of this medication for various neuropathic pain states has led to its widespread use in a number of non-neuropathic pain states as well; however, in general gabapentin has not been as effective in these disorders. For example, a single dose of gabapentin (1200 mg) or placebo was administered to individuals before mastectomy surgery. During the postoperative period, no significant difference was seen between the two groups with respect to pain levels or morphine administration. ${ }^{96}$

\section{Carbamazepine}

Carbamazepine was FDA-approved for the treatment of idiopathic trigeminal neuralgia over 30 years ago. Four small, placebo-controlled clinical trials have been completed. In one study (with doses titrated to a maximal dose of $1 \mathrm{~g} /$ day), 19 of 27 patients had a complete or very good response compared with placebo on five days' treatment. ${ }^{97}$ In a separate study using a crossover design in which the maximum dose was $2.4 \mathrm{~g} /$ day, 15 of 20 patients who received carbamazepine had a good or excellent response on 14 days' treatment. ${ }^{98}$ A separate randomized controlled study measured results utilizing pain scores. With doses in the range of 400-800 mg/day for two weeks, the mean reduction in maximum pain intensity was $58 \%$ with carbamazepine, compared with $26 \%$ on placebo.

In other trials, carbamazepine was compared with tizanidine (carbamazepine was better), ${ }^{99}$ tocainide (no difference), ${ }^{100}$ and pimozide (carbamazepine was inferior). ${ }^{101}$ In a randomized, controlled study of 30 patients with painful diabetic neuropathy, Rull et al. ${ }^{102}$ observed that after 14 days of treatment, as many as 50\% more patients improved on carbamazepine.

Carbamazepine has not been formally studied as a single agent in the treatment of PHN. In a placebocontrolled study of post-stroke pain, carbamazepine was shown to be more effective than placebo but equivalent to amitriptyline. ${ }^{103}$ These studies, however, are small and less rigorous than those conducted with today's standards.

\section{Topiramate}

Topiramate is FDA-approved for the prophylactic treatment of migraine headache. The recommended total 
daily dose of topiramate for the prophylactic treatment of migraine headache is $100 \mathrm{mg} /$ day given in two equally divided doses. The efficacy of topiramate for migraine headache prevention was determined from the results of two multicenter, randomized, double-blind, placebo-controlled trials. Topiramate is considered a first-line therapy for this indication. ${ }^{104}$ Other investigators ${ }^{105}$ have found topiramate to be effective in other headache types, such as cluster headache, as well.

Although several of the known mechanisms of action of topiramate, including its modulation of sodium channels, potentiation of gamma-aminobutyric acid, and glutamate blocking activity, would predict efficacy against neuropathic or other pain syndromes, study results have in fact been mixed. ${ }^{106}$ For painful diabetic neuropathy, most studies have yielded negative results. ${ }^{107,108}$

Topiramate was shown to possibly be effective in pain associated with chronic lumbar radiculopathy in a double-blind, randomized, two-period crossover trial in doses of 50-400 mg compared with active placebo (diphenhydramine). However, the high study dropout rate and high incidence of side effects made the authors question the usefulness of this agent in this setting. ${ }^{109}$ In a more recently published randomized, double-blind, placebo-controlled study of 96 patients with chronic low back pain, ${ }^{110}$ topiramate appeared to be helpful. In this study, important changes were noted not only in pain sensitivity but in anger status and processing as well. In summary, the strongest support for topiramate is its use in migraine prophylaxis.

\section{Divalproex sodium}

Divalproex sodium is indicated for the prophylactic treatment of migraine headache. The once-a-day extended release formulation is particularly convenient and an intravenous formulation is also available for acute migraine. A comprehensive review of studies of valproate in migraine has been completed by Rothrock. ${ }^{111}$ There are minimal data to support efficacy of divalproate for the treatment of nonheadache pain syndromes.

\section{Phenytoin}

Two randomized controlled studies of phenytoin in the management of painful diabetic neuropathy have been reported with mixed results. ${ }^{112,113}$ A third study demonstrated the potential benefit of this medication when administered intravenously for the treatment of an acute exacerbation of various different types of neuropathic pain. These patients received a $15 \mathrm{mg} / \mathrm{kg}$ dose of phenytoin intravenously over a two-hour period. ${ }^{114}$

\section{Lamotrigine}

The use of lamotrigine in various pain syndromes has been associated with mixed results. For central poststroke pain, painful human immunodeficiency virus neuropathy, trigeminal neuralgia, and spinal cord injury pain, there is reasonable evidence of efficacy. However, a notable randomized, double-blind, placebo-controlled eight-week study in patients with various neuropathic pain syndromes at doses of $200 \mathrm{mg} /$ day showed no significant benefit for lamotrigine. ${ }^{115-120}$

\section{Oxcarbazepine}

Oxcarbazepine may be effective in the management of trigeminal neuralgia and painful diabetic neuropathy, as demonstrated in small clinical trials, and should be considered when other agents have failed to control the pain of affected patients. ${ }^{121,122}$

\section{Zonisamide, levetiracetam, and tiagabine}

At this time, no significant studies have been published reporting the benefit of these agents for chronic painful conditions.

\section{CONCLUSIONS}

Select antiepileptic agents have utility in specific psychiatric and chronic pain syndromes. For most conditions described in this review, additional large, well-designed placebo-controlled trials are needed to clarify further the potential benefits of these agents.

\section{REFERENCES}

1. Ballenger JC, Post RM. Carbamazepine in manic-depressive illness: a new treatment. Am J Psychiatry 1980;137:782-790.

2. Goodnick PJ. Anticonvulsants in the treatment of bipolar mania. Expert Opin Pharmacother 2006;7:401-410.

3. Rush AJ, Fava M, Wisniewski SR, et al. Sequenced treatment alternatives to relieve depression $\left(\mathrm{STAR}^{*} \mathrm{D}\right)$ : rationale and design. Control Clin Trials 2004;25:119-142.

4. Rush AJ, Trivedi M, Fava M. Depression, IV: STAR*D treatment trial for depression. Am J Psychiatry 2003;160:237.

5. Swartz MS, Perkins DO, Stroup TS, McEvoy JP, Nieri JM, Haak DC. Assessing clinical and functional outcomes in the Clinical Antipsychotic Trials of Intervention Effectiveness (CATIE) schizophrenia trial. Schizophr Bull 2003;29:33-43.

6. Toczek MT, Carson RE, Lang L, et al. PET imaging of 5-HT1A receptor binding in patients with temporal lobe epilepsy. Neurology 2003;60:749-756.

7. Sargent PA, Kjaer KH, Bench CJ, et al. Brain serotonin1A receptor binding measured by positron emission tomography with [11C]WAY-100635: effects of depression and antidepressant treatment. Arch Gen Psychiatry 2000;57:174-180.

8. Dailey JW, Reither MEA, Yan QS, Li MY, Jobe PC. Anticonvulsant doses of carbamazepine increase hippocampal extracellular serotonin in genetically epilepsy-prone rats: dose response relationships. Neurosci Lett 1997;226:13-16.

9. Southam E, Kirkby D, Higgins GA, Hagan RM. Lamotrigine inhibits monoamine uptake in vitro and modulates 5-hydroxytryptamine uptake in rats. Eur J Pharmacol 1998;358:19-24.

10. Whitton PS, Fowler LJ. The effect of valproic acid on 5-hydroxytryptamine and 5-hydroxyindoleacetic acid concentration in hippocampal dialysates in vivo. Eur J Pharmacol 1991;200:167-169.

11. Yan QS, Mishra PK, Burger RL, Bettendorf AF, Jobe PC, Dailey JW. Evidence that carbamazepine and antiepilepsirine may produce a component of their anticonvulsant effects by activating serotonergic neurons in genetically epilepsy-prone rats. J Pharmacol Exp Ther 1992;261:652-659.

12. Naritoku DK, Terry WJ, Helfert RH. Regional induction of fos immunoreactivity in the brain by anticonvulsant stimulation of the vagus nerve. Epilepsy Res 1995;22:53-62. 
13. Browning RA, Clark KB, Naritoku DK, Smith DC, Jenson RA. Loss of anticonvulsant effect of vagus nerve stimulation in the pentylenetetrazol seizure model following treatment with 6-hydroxydopamine or 5,7-dihyrdroxy-tryptamine. Soc Neurosci 1997;23:2424.

14. Nahas Z, Marangell LB, Husain MM, et al. Two-year outcome of vagus nerve stimulation (VNS) for treatment of major depressive episodes. J Clin Psychiatry 2005;66:1097-1104.

15. Reynolds EH, Trimble MR. Adverse neuropsychiatric effects of anticonvulsant drugs. Pharmacol Biochem Behav 1985;23:21-26.

16. Hauser P, Devinsky O, DeBellis M, et al. Benzodiazepine withdrawal delirium with catatonic features. Arch Neurol 1989;46: 696-699.

17. Bowden CL, Calabrese JR, McElroy SL, et al. A randomized, placebo-controlled 12-month trial of divalproex and lithium in treatment of outpatients with bipolar I disorder. Divalproex Maintenance Study Group. Arch Gen Psychiatry 2000;57:481-489.

18. Findling RL, McNamara NK, Youngstrom EA, et al. Doubleblind 18-month trial of lithium versus divalproex maintenance treatment in pediatric bipolar disorder. J Am Acad Child Adolesc Psychiatry 2005;44:409-417.

19. Winsberg ME, DeGolia SG, Strong CM, Ketter TA. Divalproex therapy in medication-naive and mood-stabilizer-naive bipolar II depression. J Affect Disord 2001;67:207-212.

20. Porsteinsson AP, Tariot PN, Erb R, et al. Placebo-controlled study of divalproex sodium for agitation in dementia. Am J Geriatr Psychiatry 2001;9:58-66.

21. Sival RC, Haffmans PM, Jansen PA, Duursma SA, Eikelenboom P. Sodium valproate in the treatment of aggressive behavior in patients with dementia--a randomized placebo controlled clinical trial. Int J Geriatr Psychiatry 2002;17:579-585.

22. Hollander E, Tracy KA, Swann AC, et al. Divalproex in the treatment of impulsive aggression: efficacy in cluster B personality disorders. Neuropsychopharmacology 2003;28:1186-1197.

23. Baetz M, Bowen RC. Efficacy of divalproex sodium in patients with panic disorder and mood instability who have not responded to conventional therapy. Can J Psychiatry 1998;43:73-77.

24. Woodman CL, Noyes R Jr. Panic disorder: treatment with valproate. J Clin Psychiatry 1994;55:134-136.

25. Mishory A, Yaroslavsky Y, Bersudsky Y, Belmaker RH. Phenytoin as an antimanic anticonvulsant: a controlled study. Am J Psychiatry 2000;157:463-465.

26. Mishory A, Winokur M, Bersudsky Y. Prophylactic effect of phenytoin in bipolar disorder: a controlled study. Bipolar Disord 2003;5:464-467.

27. Nemets B, Bersudsky Y, Belmaker RH. Controlled double-blind trial of phenytoin vs. fluoxetine in major depressive disorder. J Clin Psychiatry 2005;66:586-590.

28. Stanford MS, Helfritz LE, Conklin SM, et al. A comparison of anticonvulsants in the treatment of impulsive aggression. Exp Clin Psychopharmacol 2005;13:72-77.

29. Kowatch RA, Suppes T, Carmody TJ, et al. Effect size of lithium, divalproex sodium, and carbamazepine in children and adolescents with bipolar disorder. J Am Acad Child Adolesc Psychiatry 2000;39:713-720.

30. Ketter TA, Kalali AH, Weisler RH. A 6-month, multicenter, open-label evaluation of beaded, extended-release carbamazepine capsule monotherapy in bipolar disorder patients with manic or mixed episodes. J Clin Psychiatry 2004;65:668-673.

31. Gajwani P, Forsthoff A, Muzina D, et al. Antiepileptic drugs in mood-disordered patients. Epilepsia 2005;46(suppl 4):38-44.

32. Greil W, Kleindienst N, Erazo N, Muller-Oerlinghausen B. Differential response to lithium and carbamazepine in the prophylaxis of bipolar disorder. J Clin Psychopharmacol 1998;18:455460.

33. Hartong EG, Moleman P, Hoogduin CA, Broekman TG, Nolen WA. Prophylactic efficacy of lithium versus carbamazepine in treatment-naive bipolar patients. J Clin Psychiatry 2003;64:144151.

34. Weisler RH, Kalali AH, Ketter TA. A multicenter, randomized, double-blind, placebo-controlled trial of extended-release carbamazepine capsules as monotherapy for bipolar disorder patients with manic or mixed episodes. J Clin Psychiatry 2004;65:478-484.

35. Weisler RH, Keck PE Jr, Swann AC, Cutler AJ, Ketter TA, Kalali AH. Extended-release carbamazepine capsules as monotherapy for acute mania in bipolar disorder: a multicenter, randomized, double-blind, placebo-controlled trial. J Clin Psychiatry 2005;66: 323-330.

36. Ettinger AB, Bernal OG, Andriola MR, et al. Two cases of nonconvulsive status epilepticus in association with tiagabine therapy. Epilepsia 1999;40:1159-1162.

37. Rosenthal M. Tiagabine for the treatment of generalized anxiety disorder: a randomized, open-label, clinical trial with paroxetine as a positive control. J Clin Psychiatry 2003;64:1245-1249.

38. Suppes T, Chisholm KA, Dhavale D, et al. Tiagabine in treatment refractory bipolar disorder: a clinical case series. Bipolar Disord 2002;4:283-289.

39. Grunze H, Erfurth A, Marcuse A, Amann B, Normann C, Walden J. Tiagabine appears not to be efficacious in the treatment of acute mania. J Clin Psychiatry 1999;60:759-762.

40. Pande AC, Davidson JRT, Jefferson JW, et al. Treatment of social phobia with gabapentin: a placebo controlled study. J Clin Psychopharmacol 1999;19:341-348.

41. Chouinard G, Beauclair L, Belanger M-C. Gabapentin: long-term antianxiety and hypnotic effects in psychiatric patients with comorbid anxiety-related disorders. Can J Psychiatry 1998:43;305.

42. Chatterjee CR, Ringold AL. A case report of reduction in alcohol craving and protection against alcohol withdrawal by gabapentin. J Clin Psychiatry 1999;60:617.

43. Mariani JJ, Rosenthal RN, Tross S, Singh P, Anand OP. A randomized, open-label, controlled trial of gabapentin and phenobarbital in the treatment of alcohol withdrawal. Am J Addict 2006; 15:76-84.

44. Moretti R, Torre P, Antonello RM, Cazzato G, Bava A. Gabapentin for the treatment of behavioural alterations in dementia: preliminary 15-month investigation. Drugs Aging 2003;20:10351040.

45. Rickels K, Pollack MH, Feltner DE, et al. Pregabalin for treatment of generalized anxiety disorder: a 4-week, multicenter, double-blind, placebo-controlled trial of pregabalin and alprazolam. Arch Gen Psychiatry 2005;62:1022-1030.

46. Pohl RB, Feltner DE, Fieve RR, Pande AC. Efficacy of pregabalin in the treatment of generalized anxiety disorder: double-blind, placebo-controlled comparison of BID versus TID dosing. J Clin Psychopharmacol 2005;25:151-158.

47. Calabrese JR, Bowden CL, Sachs GS, et al. A double-blind placebo-controlled study of lamotrigine monotherapy in outpatients with bipolar I depression. J Clin Psychiatry 1999;60:7988.

48. McElroy SL, Zarate CA, Cookson J, et al. A 52-week, open-label continuation study of lamotrigine in the treatment of bipolar depression. J Clin Psychiatry 2004;65:204-210.

49. Calabrese JR, Bowden CL, Sachs G, et al. A placebo-controlled 18-month trial of lamotrigine and lithium maintenance treatment in recently depressed patients with bipolar I disorder. J Clin Psychiatry 2003;64:1013-1024.

50. Bowden CL, Calabrese JR, Sachs G, et al. A placebo-controlled 18-month trial of lamotrigine and lithium maintenance treatment in recently manic or hypomanic patients with bipolar I disorder. Arch Gen Psychiatry 2003;60:392-400.

51. Gates JR, Folland C, Ankenbauer JL, Moriarty GL, Penovich PE. Behavioral side effects of levetiracetam. Epilepsia 2002;43(suppl 7): 187.

52. McBride AE, Perrine KR, Gunning-Dixon FM, Hamann J, Risbrook DN, Ettinger AB. Positive psychotropic effects associated with the use of lamotrigine in a clinical setting. Epilepsia 2002; 43(suppl 7):95-96.

53. Mula M, Trimble MR, Yuen A, Liu RSN, Sander JWAS. Psychiatric adverse events during levetiracetam therapy. Neurology 2003;61:704-706.

54. Kossoff EH, Bergey GK, Freeman JM, Vining EP. Levetiracetam psychosis in children with epilepsy. Epilepsia 2001;42:16111613.

55. Bersani G. Levetiracetam in bipolar spectrum disorders: first ev- 
idence of efficacy in an open, add-on study. Hum Psychopharmacol 2004;19:355-356.

56. Grunze H, Langosch J, Born C, Schaub G, Walden J. Levetiracetam in the treatment of acute mania: an open add-on study with an on-off-on design. J Clin Psychiatry 2003;64:781-784.

57. Simon NM, Worthington JJ, Doyle AC, et al. An open-label study of levetiracetam for the treatment of social anxiety disorder. J Clin Psychiatry 2004;65:1219-1222.

58. McElroy SL, Suppes T, Keck PE Jr, et al. Open-label adjunctive zonisamide in the treatment of bipolar disorders: a prospective trial. J Clin Psychiatry 2005;66:617-624.

59. Anand A, Bukhari L, Jennings SA, et al. A preliminary open-label study of zonisamide treatment for bipolar depression in $10 \mathrm{pa}-$ tients. J Clin Psychiatry 2005;66:195-198.

60. Spina E, Perugi G. Antiepileptic drugs: indications other than epilepsy. Epileptic Disord 2004;6:57-75.

61. Benedetti A, Lattanzi L, Pini S, Musetti L, Dell'Osso L, Cassano GB. Oxcarbazepine as add-on treatment in patients with bipolar manic, mixed or depressive episode. J Affect Disord 2004;79: 273-277.

62. Hummel B, Walden J, Stampfer R, et al. Acute antimanic efficacy and safety of oxcarbazepine in an open trial with an on-off-on design. Bipolar Disord 2002;4:412-417.

63. Bahk WM, Shin YC, Woo JM, et al. Topiramate and divalproex in combination with risperidone for acute mania: a randomized open-label study. Prog Neuropsychopharmacol Biol Psychiatry 2005;29:115-121

64. Chengappa KN, Rathore D, Levine J, et al. Topiramate as add-on treatment for patients with bipolar mania. Bipolar Disord 1999; $1: 42-53$.

65. McElroy SL, Suppes T, Keck PE, et al. Open-label adjunctive topiramate in the treatment of bipolar disorders. Biol Psychiatry 2000;47:1025-1033.

66. McIntyre RS, Mancini DA, McCann S, Srinivasan J, Sagman D, Kennedy SH. Topiramate versus bupropion SR when added to mood stabilizer therapy for the depressive phase of bipolar disorder: a preliminary single-blind study. Bipolar Disord 2002;4: 207-213.

67. Kamini V, Karine M, John G, Stuart W, Allan Y. Topiramate for acute affective episodes in bipolar disorder. Cochrane Database Syst Rev 2006:CD003384.

68. Dursun SM, Devarajan S. Accelerated weight loss after treating refractory depression with fluoxetine plus topiramate: possible mechanisms of action? Can J Psychiatry 2001;46:287-288.

69. Kanner AM, Wuu J, Faught E, Tatum WO, Fix A, French JA. A past psychiatric history may be a risk factor for topiramate-related psychiatric and cognitive adverse events. Epilepsy Behav 2003; 4:548-552.

70. Reith D, Burke C, Appleton DB, Wallace G, Pelekanos J. Tolerability of topiramate in children and adolescents. J Paediatr Child Health 2003;39:416-419.

71. Kober D, Gabbard GO. Topiramate-induced psychosis. Am J Psychiatry 2005;162:1542.

72. Stella F, Caetano D, Cendes F, Guerreiro CA. Acute psychotic disorders induced by topiramate: report of two cases. Arq Neuropsiquiatr 2002;60:285-287.

73. Besag FM. Behavioural effects of the newer antiepileptic drugs: an update. Expert Opin Drug Saf 2004;3:1-8.

74. Hofer A, Fleischhacker WW, Hummer M. Worsening of psychosis after replacement of adjunctive valproate with topiramate in a schizophrenia patient. J Clin Psychiatry 2003;64:1267-1268.

75. Duggal HS, Singh I. Worsening of psychosis or topiramate-induced adverse event? Gen Hosp Psychiatry 2004;26:245-247.

76. Nickel MK, Nickel C, Mitterlehner FO, et al. Topiramate treatment of aggression in female borderline personality disorder patients: a double-blind, placebo-controlled study. J Clin Psychiatry 2004;65:1515-1519.

77. Nickel MK, Nickel C, Kaplan P, et al. Treatment of aggression with topiramate in male borderline patients: a double-blind, placebo-controlled study. Biol Psychiatry 2005;57:495-499.

78. Janowsky DS, Kraus JE, Barnhill J, Elamir B, Davis JM. Effects of topiramate on aggressive, self-injurious, and disruptive/de- structive behaviors in the intellectually disabled: an open-label retrospective study. J Clin Psychopharmacol 2003;23:500-504.

79. Berlant JL. Prospective open-label study of add-on and monotherapy topiramate in civilians with chronic nonhallucinatory posttraumatic stress disorder. BMC Psychiatry 2004;4:24.

80. Rush AJ, George MS, Sackeim HA, et al. Vagus nerve stimulation (VNS) for treatment-resistant depression: a multicenter study. Biol Psychiatry 2000;47:276-286.

81. George MS, Rush AJ, Marangell LB, et al. A one-year comparison of vagus nerve stimulation with treatment as usual for treatment-resistant depression. Biol Psychiatry 2005;58:364-373.

82. Backonja MM. Use of anticonvulsants for treatment of neuropathic pain. Neurology 2002;59(suppl 2): S14-17.

83. Dworkin RH, Corbin AE, Young JP Jr, et al. Pregabalin for the treatment of postherpetic neuralgia: a randomized, placebo-controlled trial. Neurology 2003;60:1274-1283.

84. Sabatowski R, Galvez R, Cherry DA, et al. Pregabalin reduces pain and improves sleep and mood disturbances in patients with post-herpetic neuralgia: results of a randomized, placebo-controlled trial. Pain 2004;109:26-35.

85. Rosenstock J, Tuchman M, LaMoreaux L, et al. Pregabalin for the treatment of painful diabetic peripheral neuropathy: a doubleblind, placebo-controlled trial. Pain 2004;110:628-638.

86. Lesser H, Sharma U, LaMoreaux L, et al. Pregabalin relieves symptoms of painful diabetic neuropathy: a randomized controlled trial. Neurology 2004;63:2104-2110.

87. Richter RW, Portenoy R, Sharma U, et al. Relief of painful diabetic peripheral neuropathy with pregabalin: a randomized, placebo-controlled trial. J Pain 2005;6:253-260.

88. Van Seventer R, Feister HA, Young JP Jr, et al. Efficacy and tolerability of twice-daily pregabalin for treating pain and related sleep interference in postherpetic neuralgia: a 13-week randomized trial. Curr Med Res Opin 2006;22:375-384.

89. Crofford LJ, Rowbotham MC, Mease PJ, et al. Pregabalin for the treatment of fibromyalgia syndrome: results of a randomized, double-blind, placebo-controlled trial. Arthritis Rheum 2005;52: $1264-1273$

90. Rice AS, Maton S, Postherpetic Neuralgia Study Group. Gabapentin in postherpetic neuralgia: a randomised, double-blind, placebo-controlled study. Pain 2001;94:215-224.

91. Rowbotham M, Harden N, Stacey B, et al. Gabapentin for the treatment of postherpetic neuralgia: a randomized controlled trial. JAMA 1998;280:1837-1842.

92. Backonja M, Beydound A, Edwards KR, et al. Gabapentin for the symptomatic treatment of painful neuropathy in patients with diabetes mellitus: a randomized controlled trial. JAMA 1998;280: $1831-1836$.

93. Gilron I, Flatters SJ. Gabapentin and pregabalin for the treatment of neuropathic pain: a review of laboratory and clinical evidence. Pain Res Manag 2006;11(suppl A):16A-29A.

94. Smith DG, Ehde DM, Hanley MA, et al. Efficacy of gabapentin in treating chronic phantom limb and residual limb pain. J Rehabil Res Dev 2005;42:645-654.

95. Mathew NT, Rapoport A, Saper J, et al. Efficacy of gabapentin in migraine prophylaxis. Headache 2001;41:119-128.

96. Dirks J, Fredensborg BB, Christensen D, Fomsgaard JS, Flyger H, Dahl JB. A randomized study of the effects of single-dose gabapentin versus placebo on postoperative pain and morphine consumption after mastectomy. Anesthesiology 2002;97: $560-564$.

97. Killian JM, Fromm GH. Carbamazepine in the treatment of neuralgia. Use and side effects. Arch Neurol 1968;19:129-136.

98. Nicol 1969 CF. A four year double blind study of Tegretol in facial pain. Headache 1969;9:54-57.

99. Vilming ST, Lyberg T, Lataste X. Tizanidine in the management of trigeminal neuralgia. Cephalgia 1986;6:181-182.

100. Lindsrom $P$, Lindblom $U$. The analgesic effect of tocainide in trigeminal neuralgia. Pain 1987;28:45-50.

101. Lechin F, van der Dijs B, Lechin ME, et al. Pimozide therapy for trigeminal neuralgia. Arch Neurol 1989;46:960-963.

102. Rull J, Quibrera R, Gonzalez-Millan H, et al. Symptomatic treatment of peripheral diabetic neuropathy with carbamazepine: double-blind crossover study. Diabetologia 1969;5:215-220. 
103. Leijon G, Boivie J. Central post-stroke pain- a controlled trial of amitriptyline and carbamazepine. Pain 1989;28:45-50.

104. Silberstein SD. Topiramate in migraine prevention. Headache 2005;45(suppl 1):S57-65.

105. Mathew NT, Kailasam J, Meadors L. Prophylaxis of migraine, transformed migraine and cluster headache with topiramate. Headache 2002;42:796-803.

106. Chong MS, Libretto SE. The rationale and use of topiramate for treating neuropathic pain. Clin J Pain 2003;19:59-68.

107. Thienel U, Neto W, Schwabe SK, et al. Topiramate in painful diabetic polyneuropathy: findings from three double-blind placebo controlled trials. Acta Neurol Scand 2004;10:221-231.

108. Raskin P, Donofrio PD, Rosenthal N, et al. Topiramate vs placebo in painful diabetic neuropathy: analgesic and metabolic effects. Neurology 2004;63:865-873.

109. Khoromi S, Patsalides A, Parada S, et al. Topiramate in chronic lumbar radicular pain. J Pain 2005;6:829-836.

110. Muehlbacher M, Nickel MK, Kettler C, et al. Topiramate in treatment of patients with chronic low back pain: a randomized, double-blind, placebo-controlled study. Clin J Pain 2006;22:526531.

111. Rothrock JF. Clinical studies of valproate for migraine prophylaxis. Cephalalgia 1997;17:81-83.

112. Chadda VS, Mathur M. Double-blind study of the effects of diphenylhydantoin sodium on diabetic neuropathy. J Assoc Physicans India 1978;26:403-406.

113. Saudek CD, Werns S, Reidenberg MM. Phenytoin in the treatment of diabetic symmetrical neuropathy. Clin Pharmacol Ther 1977;22:196-199.
114. McCleane GJ. Intravenous infusion of phenytoin relieves neuropathic pain: a randomized, double-blind, placebo-controlled, crossover study. Anesth Analg 1999;89:985-988.

115. Vestergaard K, Andersen G, Gottrup H, et al. Lamotrigine for central poststroke pain: a randomized controlled trial. Neurology 2001;56:184-190.

116. Simpson DM, McArthur JC, Olney R, et al. Lamotrigine for HIV-associated painful sensory neuropathies: a placebo-controlled trial. Neurology 2003;60:1508-1514.

117. Zakrzewska JM, Chaudhry Z, Nurmikko TJ, et al. Lamotrigine (Lamictal) in refractory trigeminal neuralgia: results from a double-blind placebo-controlled crossover trial. Pain 1997;73:223230 .

118. Sindrup SH, Jensen TS. Pharmacotherapy of trigeminal neuralgia. Clin J Pain 2002;18:22-27

119. Finnerup NB, Sindrup SH, Bach FW, et al. Lamotrigine in spinal cord injury pain: a randomized controlled trial. Pain 2002;96: 375-383.

120. McCleane G. $200 \mathrm{mg}$ daily of lamotrigine has no analgesic effect in neuropathic pain: a randomized, double-blind placebo controlled trial. Pain 1999;83:105-107.

121. Zakrzewska JM, Pansalos PN. Oxcarbazepine: a new drug in the management of intractable trigeminal neuralgia. J Neurol Neurosurg Psychiatry 1989;52:472-476.

122. Dogra S, Beydoun S, Mazzola J, et al. Oxcarbazepine in painful diabetic neuropathy: a randomized, placebo-controlled study. Eur J Pain 2005;9:543-554 